\title{
THE CHARACTERISTICS OF AHMAD TOHARI'S SMILE SHORT STORY BY AHMAD TOHARI
}

\author{
Ahmad Khoiril Anam, \\ Universitas Indraprasta PGRI \\ Yogi Purnama*), \\ Universitas Indraprasta PGRI \\ *) Correspondences author: Jalan Nangka 58 Tanjung Barat, Jakarta Selatan; Indonesia \\ e-mail: yogipurnama035@gmail.com
}

\begin{abstract}
The purpose of this study is to describe the characters contained in the collection of short stories Senyum Karyamin by Ahmad Tohari. The method used in this research is qualitative descriptive research. The research technique used is the analysis of the contents of collection of short stories and literature studies to find and collect library data in the form of books relating to research sebjects. Research on the characterization of the main characters in a collection of short stories with the use of analytical and dramatic aspects of the story of thirteen sub-chapters. The results found the chacarterization of the main characters in a short stories with use of analytical aspects of 53 findings (51\%) and dramatic 51 findings (49\%) that appear in the story of thirteen sub-chapters that exist. Short collection of Senyum Karyamin depicts the character of rural communities that reflect daily life.
\end{abstract}

Keywords: Main Character, Analytical Aspects, Dramatic Aspects, Short Stories Senyum Karyamin.

Article History: Received: 17/06/2021; Revised: 21/06/2021; Accepted: 28/06/2021; Published: 30/06/2021.

How to Cite (MLA 7 ${ }^{\text {th }}$ ): Anam, Ahmad Khoiril, and Yogi Purnama. "The Characteristics of Ahmad Tohari's Smile Short Story by Ahmad Tohari." Hortatori Jurnal Pendidikan Bahasa dan Sastra Indonesia 5.1 (2021): 8-13. Print/Online. Copyrights Holder: Ahmad Khoiril Anam, Yogi Purnama. First Publication: Hortatori Jurnal Pendidikan Bahasa dan Sastra Indonesia (2017).

This work is licensed under a Creative Commons Attribution-ShareAlike 4.0 International License.

\section{Pendahuluan}

Karya sastra sangat berkaitan dengan kemampuan imajinasi pengarang dalam mengumpulkan pengalaman yang dilihat dan dirasakan untuk menjadikan karya sastra sebagai satu kesatuan yang utuh. Karya sastra imajinatif merupakan karya yang menyajikan kehidupan manusia dengan permasalahannya (Wahyuningsih). Proses imajinasi melahirkan estetika karya sastra yang tumbuh melalui pengalaman pada diri pengarang. Pada dasarnya sastra dibagi menjadi dua yaitu sastra imajinatif dan sastra nonimajinatif. Sastra imajinatif adalah karya yang tipis hubungannya dengan fakta maupun realitas kehidupan bentuk karya sastra tersebut antara lain puisi dan prosa. Sastra nonimajinatif merupakan karya yang bekerja berdasarkan fakta maupun realitas kehidupan.

Karya sastra berupa cerpen merupakan karya nonimajinatif yang berbentuk fiksi. Cerita pendek identik dengan secara langsung memusatkan pada satu kejadian, penulis biasanya membuat tokoh yang terbatas, dengan jangka waktu yang sangatlah singkat. Cerpen adalah cerita pendek yang menceritakan sebagian kecil dari kisah pelaku utamanya (Dibia, 2018:76). Berdasarkan pendapat tersebut bahwa pelaku utama diceritakan pada cerpen dengan mengubah sikap pemeran utama dalam konflik tertentu. Cerpen memiliki konflik yang relatif lebih singkat dibandingkan oleh novel. Biasanya dalam cerpen hanya menceritakan rekaan yang berdasarkan realita kehidupan. Ketika membaca sebuah cerpen tidak hanya sekadar membaca kisah lamunan tetapi dapat menunjukkan sisi kenyataan. Oleh karena itu, cerpen dapat 
menggambarkan tentang suatu kenyataan dan peristiwa kehidupan bermasyarakat. Unsur-unsur yang membangun cerpen itu sendiri terdiri dari tema, latar, alur, perwatakan atau karakter, tokoh, amanat.

Hal yang sering diperhatikan dalam cerpen salah satunya adalah karakteristik tokoh. Watak merupakan sifat dasar, karakter seseorang, perilaku, atau budi pekerti yang dimiliki oleh tokoh dalam cerita (Priyatni, 2010:111). Dari karakteristik tokoh nanti dapat terlihat amanat yang terkandung dalam cerpen tersebut. Tokoh dapat menjadi sentral pada sebuah cerpen. Tokoh adalah pelaku dalam cerita fiksi yang membuat peristiwa sehingga mampu untuk merangkai sebuah cerita (Aminuddin dalam Rokhmansyah, 2014:34). Melalui karakter tokoh pengarang dapat merangkai peristiwa yang berlangsung dalam sebuah cerpen. Dengan adanya penggambaran karakter tokoh utama pengarang dapat menuliskan pesan kepada pembacanya, salah satunya adalah karya dari Ahmad Tohari. Cerpen karya Ahmad Tohari dalam kumpulan cerpen Senyum Karyamin banyak membuat sebuah cerita yang memperlihatkan kehidupan bagi penikmatnya. Kekuatan karya Ahmad Tohari dapat dilihat dari penggunaan latar alam serta karakter tokoh utama yang disajikan pengarang memiliki keunikan karena karakter tersebut menyiratkan kehidupan masyarakat. Dari karakter tokoh tersebut juga tersirat amanat yang disampaikan oleh pengarang.

Cerpen karya Ahmad Tohari memiliki bahasa yang lugas dan sederhana. Ahmad Tohari selalu membuat sebuah cerita yang memperlihatkan kehidupan bagi penikmatnya. Kekuatan karya Ahmad Tohari dapat di lihat dari penggunaan latar alam dengan memperlihatkan flora dan fauna. Kumpulan cerpen Senyum Karyamin terdiri dari 13 cerpen yaitu; Senyum Karyamin, Jasa-Jasa buat Sanwirya, Si Minem Beranak Bayi, Surabanglus, Tinggal Matanya Berkedip-kedip, Ah, Jakarta, Blokeng, Syukuran Sutabawor, Rumah yang Terang, Kenthus, Orang-Orang Seberang Kali, Wangon Jatilawang, Pengemis dan Shalawat Badar. Situasi dalam ruang atau waktu yang diangkat pengarang cukup familiar untuk dikaji. Kehidupan pedesaan dan kehidupan orang-orang kecil yang sederhana serta latar alamnya peneliti ingin melihat keterkaitan lewat karakter yang diperlihatkan.

Metode karakteristik dalam telaah sastra merupakan metode yang melukiskan para tokoh yang terdapat dalam karya sastra. karakterisasi tokoh dapat dilakukan melalui dua cara yakni metode langsung (analitik) dan metode tidak langsung (dramatik). Metode langsung yang digunakan untuk pemaparan watak tokoh pada eksposisi yang langsung diberikan komentar dari pengarang. Pemarapan dalam metode analitik dilakukan secara langsung oleh pengarang atau bantuan dari narator. Metode tidak langsung (metode dramatik) merupakan metode penempatan diri pengarang pada luar kisah yang diperlihatkan yang bertujuan memberikan kesempatan kepada tokoh dalam mengeksplor dialog yang ditampilkan melalui perwatakan tokoh tindakan (action) (Pickering dan Hoeper dalam Minderop, 2011: 6).

Dengan adanya penampilan karakter tokoh yang menarik pada cerita fiksi, maka peristiwa dalam cerita akan hidup dan mampu "menjahit" cerita secara utuh dan kokoh. Dengan adanya karakter tokoh yang menarik pada cerita fiksi, maka peristiwa dalam cerita akan hidup dan mampu menjalin suatu cerita yang utuh dan kokoh. Dengan menonjolkan karakter tokoh, pengarang mampu melahirkan konflik dalam cerita yang dapat berubah-ubah, baik situasi, penampilan tokoh, jati diri, dialek/bahasa, tindakan, maupun tingkah laku tokoh terhadap suatu keadaan. Konflik tercipta pada tokoh utama atau tokoh protagonis yang sangat kental. Protagonis menjadi tokoh sentral dalam sebuah cerita (Angsa). Dengan demikian penelitian ini akan menguraikan tentang karakter tokoh menggunakan teknik analitik dan dramatik dalam antologi cerpen Senyum Karyamin karya Ahmad Tohari.

\section{Metode}

Metode penelitian yang digunakan penulis adalah metode kualitatif deskriptif analisis isi dengan pendekatan struktural yang ditujukan untuk menganalisis karakter tokoh baik secara langsung (aspek analitik) maupun secara tidak langsung (aspek dramatik). Pengumpulan data yang dilakukan dengan membaca dan mencatat isi dari kumpulan cerpen Senyum Karyamin karya Ahmad Tohari. Selanjutnya penulis mendeskripsikan karakter tokoh utama. Cerpen ini berjumlah 88 halaman, 13 subbab judul, dan diterbitkan pada tahun 2019 oleh penerbit Gramedia Pustaka Utama. Dalam hal ini peneliti menggunakan 13 subbab judul yang terdapat dalam kumpulan cerpen Senyum Karyamin karya Ahmad Tohari. Selanjutnya mencatat dan mengelompokkan aspek analitik dan dramatik yang mendeskripsikan karakter tokoh. 


\section{Hasil dan Diskusi}

Dari analisis struktur yang di dapat representasi karakter tokoh melalui aspek analitik dan dramatik karakter tokoh berikut ini:

1. Cerpen Senyum Karyamin

\section{a. Analitik}

Karyamin tak lagi membencinya karena sadar, burung yang demikian sibuk pasti sedang mencari makanbuat anak-anaknya dalam sarang entah di mana. (Hal 4)

Kutipan tokoh dan karakterisasi yang pengarang gambarkan pada cerpen ini menggunakan metode analitik melalui nama tokoh.

b. Dramatik

"Tidak, beri aku minum saja. Daganganmu sudah ciut seperti itu. Aku tak ingin menambah utang." (Hal 3)

Kutipan tokoh dan karakterisasi yang pengarang gambarkan pada cerpen ini menggunakan metode dramatik melalui tindakan.

2. Jasa-Jasa buat Sanwirya

a. Analitik

Waras melirik ke samping menatap Sampir dengan benci. (Hal 8)

Kutipan tokoh dan karakterisasi yang pengarang gambarkan pada cerpen ini menggunakan metode analitik melalui nama tokoh.

b. Dramatik

"Dengar Sampir." Kata Waras. "Kau harus menyetujui kata-kataku ini. Bahwa jasa-jasa buat Sanwirya seharusnya bukan merupakan hal yang tanggung. Semuanya baru memadai jika Sanwirya sudah memegang polis ansuransi jiwa. (Hal 10)

Kutipan tokoh dan karakterisasi yang pengarang gambarkan pada cerpen ini menggunakan metode dramatik melalui tindakan.

3. Si Minem Beranak Bayi

a. Analitik

Masih terkesan amat dalam di hati Kasdu bagaimana Minem menyeringai menahan sakit. Bagaiamana ia tutup saluran napasnya, kemudian mengerutkan urat-urat perut agar jabang bayi terdorong keluar. (Hal 14)

Kutipan tokoh dan karakterisasi yang pengarang gambarkan pada cerpen ini menggunakan metode analitik melalui nama tokoh.

b. Dramatik

“Tidak, Mak. Minem anu... melahirkan. Minem sudah melahirkan.” (Hal 15)

Kutipan tokoh dan karakterisasi yang pengarang gambarkan pada cerpen ini menggunakan metode dramatik melalui situasi.

4. Surabanglus

a. Analitik

Lega. Kimin merasa begitu lega. Ditunggunya perubahan pada wajah Suing. Ditunggunya tanda-tanda kesembuhan pada diri sahabatnya itu. (Hal 21)

Kutipan tokoh dan karakterisasi yang pengarang gambarkan pada cerpen ini menggunakan metode analitik melalui nama tokoh.

b. Dramatik

"Maka dengarlah. Aku mau lari ke kampung mencari air dan makanan untukmu. Kau menunggu di sini. Dan ingat, wanti-wanti kau tidak boleh menjamah singkong bakar itu. Mengerti?" (Hal 19)

Kutipan tokoh dan karakterisasi yang pengarang gambarkan pada cerpen ini menggunakan metode dramatik melalui jati diri.

5. Tinggal Matanya Berkedip-kedip

a. Analitik

Tangan kirinya menggoyang-goyangkan tangkai bajak. Tangan kanannya mengayunkan cambuk. Tetapi si cepon tetap tak bergerak. Masgepuk mengulangi teriakannya lebih keras. Tali kekang disentakkannya kuat-kuat. (Hal 22) 
Kutipan tokoh dan karakterisasi yang pengarang gambarkan pada cerpen ini menggunakan metode analitik melalui nama tokoh.

b. Dramatik

"Oh itu gampang. Gampang! Sampean akan melihat nanti si Cepon yang baru kujinakkan ini akan menggarap sawah kalian dengan gampang. (Hal 24)

Kutipan tokoh dan karakterisasi yang pengarang gambarkan pada cerpen ini menggunakan metode dramatik melalui tingkah laku.

6. Ah, Jakarta

a. Analitik

Dan kini aku tidak berguna menyalahkannya. Apalagi sebentar lagi kali Serayu akan banjir. Kubur karibku akan tersapu air bah. Belulangnya akan jadi anta-berantah. (Hal 32)

Kutipan tokoh dan karakterisasi yang pengarang gambarkan pada cerpen ini menggunakan metode analitik melalui tuturan pengarang.

b. Dramatik

"Sudah mati, ya matilah. Aku hanya teringat yang masih hidup." (Hal 29)

Kutipan tokoh dan karakterisasi yang pengarang gambarkan pada cerpen ini

7. Blokeng menggunakan metode dramatik melalui situasi.

a. Analitik

Blokeng tidak mengerti apa itu polisi. Tetapi dia mengerti orang-orang berseragam yang pernah menarik tangannya agar dia menyingkirkan dari onggokan sampah besar karena bupati mau datang meninjau pasar. (Hal 36)

Kutipan tokoh dan karakterisasi yang pengarang gambarkan pada cerpen ini menggunakan metode analitik melalui nama tokoh.

b. Dramatik

"Aku tak boleh berkata apa-apa. Kalau mulutku bocor dia akan memukulku dengan ini," kata Blokeng sambil menggamit lampu senter pak hansip. (Hal 35)

Kutipan tokoh dan karakterisasi yang pengarang gambarkan pada cerpen ini menggunakan metode dramatik melalui tindakan.

8. Syukuran Sutabawor

a. Analitik

Sudah bulat hatinya hendak merubuhkan pohon itu, pohon yang mandul dan tidak pernah menghasilkan apa-apa. (Hal 38)

Kutipan tokoh dan karakterisasi yang pengarang gambarkan pada cerpen ini menggunakan metode analitik melalui nama tokoh.

b. Dramatik

"Jengkol ya jengkol Pak. Aku mesti bagaimana?" (Hal 39)

Kutipan tokoh dan karakterisasi yang pengarang gambarkan pada cerpen ini menggunakan metode dramatik melalui tingkah laku.

9. Rumah yang Terang

a. Analitik

Aku tak rela ayah mendapatkan cercaan lebih banyak. (Hal 44)

Kutipan tokoh dan karakterisasi yang pengarang gambarkan pada cerpen ini menggunakan metode analitik melalui tuturan pengarang.

b. Dramatik

"Sudahlah Nak. Kamu lihat sendiri, aku hampir mati. Sepeninggalanku nanti kamu bisa secepatnya memasang listrik di rumah ini." (Hal 45)

Kutipan tokoh dan karakterisasi yang pengarang gambarkan pada cerpen ini

10. Kenthus menggunakan metode dramatik melalui situasi.

a. Analitik

Kenthus tersenyum, dadanya penuh. Lalu diambilnya selembar lima ratusan. Uang itu diacungkannya melalui pundak kepada Dawet. (Hal 48)

Kutipan tokoh dan karakterisasi yang pengarang gambarkan pada cerpen ini menggunakan metode analitik melalui nama tokoh. 
b. Dramatik

"Jijik. Jijiiiik! Apa itu mimpi nunggang macan? Kamu jadi bau tikus. Tengik dan busuk! Aku benci, benciiiiiiii!" (Hal 51)

Kutipan tokoh dan karakterisasi yang pengarang gambarkan pada cerpen ini menggunakan metode dramatik melalui nada suara.

11. Orang-Orang Seberang Kali

a. Analitik

Untuk saudaraku orang-orang seberang kali ini aku hanya bisa tersenyum dan menggerakkan kepala. (Hal 54)

Kutipan tokoh dan karakterisasi yang pengarang gambarkan pada cerpen ini menggunakan metode analitik melalui tuturan pengarang.

b. Dramatik

"Kan ajal di tangan tuhan Mas." (Hal 54)

Kutipan tokoh dan karakterisasi yang pengarang gambarkan pada cerpen ini menggunakan metode dramatik melalui jati diri.

12. Wangon Jatilawang

a. Analitik

Selesai makan, Sulam mengangkat sendiri piring dan gelasnya, lalu masuk ke dalam. Anak-anakku tak ada yang merasa takut kepadanya. Mereka sudah kenal siapa dia. (Hal 57)

Kutipan tokoh dan karakterisasi yang pengarang gambarkan pada cerpen ini menggunakan metode analitik melalui nama tokoh.

b. Dramatik

"Tapi aku bukan anak kecil, Pak. Aku wong gemblung," kata Sulam serius. (Hal 60)

Kutipan tokoh dan karakterisasi yang pengarang gambarkan pada cerpen ini menggunakan metode dramatik melalui jati diri.

13. Pengemis dan Shalawat Badar

a. Analitik

Celana, baju, dan kopiahnya berwarna hitam. Dia naik dari pintu depan. Begitu naik lelaki itu mengucapkan salam dengan fasih. Kemudian dari mulutnya mengalir Shalawat Badar dalam suara yang bening. Dan tangannya menengadah. Lelaki itu mengemis. (Hal 64)

Kutipan tokoh dan karakterisasi yang pengarang gambarkan pada cerpen ini menggunakan metode analitik melalui penampilan tokoh.

b. Dramatik

"Saya naik sendiri. tapi saya tidak ingin ikut. Saya Cuma mau ngemis kok. Coba, suruh sopir berhenti. Nanti saya akan turun. Mumpung belum jauh." (Hal 65)

Kutipan tokoh dan karakterisasi yang pengarang gambarkan pada cerpen ini menggunakan metode dramatik melalui perbuatan atau tingkah laku.

Berdasarkan hasil dari analisis struktur karakter tokoh yang terdapat dalam 13 subbab judul kumpulan cerpen Senyum Karyamin terdapat aspek analitik dan dramatik yang terkandung dalam cerpen tersebut. Jumlah tersebut dapat dilihat dalam tabel di bawah ini:

\begin{tabular}{lllc}
\multicolumn{4}{c}{ Tabel 1. Persentase Aspek Analitik dan Dramatik } \\
\hline No. & Karakter & Jumlah & Persentase \\
\hline 1 & Analitik & 53 & 50,96 \\
\hline 2 & Dramatik & 51 & 49,04 \\
\hline & Total & 104 & $100 \%$ \\
\hline
\end{tabular}




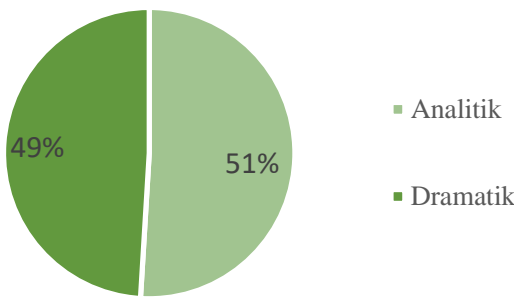

Diagram 1. Persentase Karakterisasi Tokoh

Hasil perhitungan di atas dari 13 subbab judul cerita pendek Senyum Karyamin karya Ahmad Tohari terdiri dari karakterisari tokoh dengan aspek analitik sebanyak 53 (51\%) dan aspek dramatik sebanyak $51(49 \%)$.

\section{Simpulan}

Berdasarkan hasil penelitian dan pembahasan dapat disimpulkan bahwa dari 13 subbab judul cerita pendek Senyum Karyamin karya Ahmad Tohari terdiri dari karakterisari tokoh dengan aspek analitik sebanyak $53(51 \%)$ dan aspek dramatik sebanyak 51 (49\%). Artinya, penulis, dalam hal ini adalah Ahmad Tohari lebih banyak menggambarkan karakter tokoh melalui aspek dramatik atau menggambarkan tokoh secara tidak langsung yakni metode penempatan diri pengarang pada luar kisah yang diperlihatkan yang bertujuan memberikan kesempatan kepada tokoh dalam mengeksplor dialog yang ditampilkan melalui perwatakan tokoh tindakan (action).

\section{Ucapan Terima Kasih}

Kepada semua pihak yang telah membantu dalam proses penulisan artikel ilmiah ini peneliti mengucapkan terima kasih

\section{Daftar Rujukan}

Dibia, I. Ketut. Apresiasi Bahasa dan Sastra Indonesia. Depok: Rajawali Pers, 2018.

Minderop, Albertine. Metode karakterisasi telaah fiksi. Jakarta: Yayasan Pustaka Obor Indonesia, 2005.

Purnama, Yogi, Kartono Kartono, and Sohibul Anwar. "The Main Character Inner Conflict Element in

Drama Manuscript Nyanyian Angsa Creation by Anton Chekov and the Implications Toward

Literature Teaching." Hortatori: Jurnal Pendidikan Bahasa dan Sastra Indonesia 4.1 (2020): 73 85 .

Priyatni, Endah Tri. Membaca Sastra Dengan Ancangan Literasi Kritis. Jakarta: Bumi Aksara, 2010.

Rokhmansyah, Alfian. Studi dan Pengkajian Sastra: Perkenalan Awal Terhadap Ilmu Sastra. Yogyakarta: Graha Ilmu, 2014.

Wahyuningsih, Tri Mulyani. "Makna Denotatif dan Konotatif Hana (Hidung) Pada Cerpen "Hana" Karya Akutagawa Ryunosuke." Alayasastra 16.1 (2020): 61-73. 